\title{
Intravenous flurbiprofen axetil accelerates restoration of bowel function after colorectal
} surgery

\author{
[Le flurbiprofêne axétil intraveineux accélère la restauration de la fonction intes- \\ tinale après une chirurgie colorectale]
}

Yajun Xu MD, Zhiming Tan MD PhD, Jiawei Chen MD PhD, Feifei Lou MD, Wei Chen MD

Purpose: Flurbiprofen axetil (FA) is a potent non-steroidal antiinflammatory drug (NSAID). We examined the effects that perioperative intravenous administration of FA, combined with thoracic epidural anesthesia and postoperative patient-controlled epidural analgesia (PCEA), have on bowel function, postoperative pain, and cytokine release, after open colorectal surgery.

Methods: This was a prospective, randomized, double-blind, placebo-controlled study. Forty patients were randomly assigned to one of two groups ( $n=20$ in each group). The FA group patients received FA I $\mathrm{mg} \cdot \mathrm{kg}^{-1}$ iv, 30 min before and six hours after skin incision; whereas the control group patients received an equal volume of intralipid. Blood cytokine levels were measured before FA administration, at the end of surgery, and six hours and $24 \mathrm{hr}$ postoperatively. All patients received postoperative PCEA for pain control. Analgesic efficacy was evaluated for $72 \mathrm{hr}$ postoperatively using visual analogue scale (VAS) pain scores both at rest and during coughing. Gastrointestinal motility was recorded. Temperature and leukocyte count were measured preoperatively, and $24 \mathrm{hr}$ postoperatively.

Results: The times to first bowel movement $(87 \pm 23$ vs 105 $\pm 19 \mathrm{hr}, P=0.008)$ and first flatus $(63 \pm 16 \mathrm{vs} 75 \pm 1 \mathrm{l} \mathrm{hr}$, $P=0.0 \mathrm{I})$ were earlier in the FA group compared to the control group. For the first $24 \mathrm{hr}$, the pain scores in the FA group were also lower during coughing $(P<0.001$ compared to control). The plasma concentrations of interleukin (IL)- 6 and IL-8 in the FA group were lower, postoperatively $(P<0.01$ and $P<0.05$, respectively, compared to control). In contrast, the IL-I 0 levels were significantly increased at six hours, postoperatively, in the FA group $(P=0.009)$. The total leukocyte count and the incidence of pyrexia were also lower in patients of the FA group ( $P$ $=0.00 \mathrm{I}$ and $P=0.006$, respectively, compared to control).
Conclusion: Flurbiprofen axetil may have an anti-inflammatory effect in major abdominal surgery. The combination of perioperative intravenous FA, intraoperative thoracic epidural anesthesia, and postoperative PCEA facilitated recovery of bowel function, enhanced analgesia, and attenuated the cytokine response.

CAN J ANESTH 2008/55: 7 / pp 414-422

Objectif: Le flurbiprofene axétil (FA) est un agent antiinflammatoire non stéroïdien (AINS) puissant. Nous avons évalué les effets d'une administration intraveineuse périopératoire de $F A$, en présence d'une anesthésie péridurale thoracique et d'une analgésie péridurale contrôlée par le patient (APCP) postopératoire, sur la fonction intestinale, la douleur postopératoire et la libération de cytokines à la suite d'une chirurgie colorectale ouverte.

Méthode : Nous avons mené une étude prospective, randomisée, à double insu et contrôlée par placebo. Quarante patients ont été randomisés dans deux groupes ( $n=20$ dans chaque groupe). Les patients du groupe FA ont reçu du FA I $\mathrm{mg} \cdot \mathrm{kg}^{-1}$ iv 30 min avant et six heures après l'incision de la peau; les patients du groupe témoin ont, quant à eux, reçu un volume équivalent d'Intralipide. Les niveaux de cytokines plasmatiques ont été mesurés avant l'administration de FA, à la fin de la chirurgie, et six et $24 \mathrm{~h}$ après l'opération. Tous les patients ont reçu une APCP pour le contrôle de la douleur. L'efficacité analgésique a été évaluée à $72 \mathrm{~h}$ après l'opération sur la base des scores de douleur sur une échelle visuelle analogue (EVA) au repos et à la toux. La motilité gastro-intestinale a été enregistrée. La température et la numération leucocytaire ont été mesurées avant l'opération et $24 \mathrm{~h}$ après l'opération.

From the Department of Anesthesiology, Fudan University Cancer Hospital, Shanghai, China.

Address correspondence to: Dr. Zhiming Tan, Department of Anesthesiology, Fudan University Cancer Hospital, No.270 Dong-an Road,

Shanghai, P. R. China, PC200032. Phone: 86-21-64175590; Fax: 81-21-64174774; E-mail: tan1964zm@yahoo.com.cn

This study was supported, in part, by a grant from the Ministry of Education of China, Beijing, China.

Accepted for publication March 7, 2008.

Revision accepted April 22, 2008. 
Résultats : Les temps jusqu'à la première défécation ( $87 \pm 23$ vs $105 \pm 19 \mathrm{~h}, P=0,008)$ et jusqu'aux premières flatuosités (63 \pm 16 vs $75 \pm I / h, P=0,0$ l) étaient plus courts dans le groupe $F A$ que dans le groupe témoin. Durant les 24 premières heures, les scores de douleur à la toux étaient également moindres dans le groupe FA ( $P<0,001$ par rapport au groupe témoin). Les concentrations plasmatiques d'interleukine (IL)-6 et IL-8 étaient plus basses dans le groupe $F A$ après l'opération $(P<0,01$ et $P<0,05$, respectivement, par rapport au groupe témoin). En revanche, les niveaux IL-10 étaient significativement plus élevés à six heures après l'opération dans le groupe $F A(P=0,009)$. La numération leucocytaire totale et l'incidence de pyrexie étaient également plus bas dans le groupe $F A(P=0,001$ et $P=0,006$, respectivement, par rapport au groupe témoin).

Conclusion : Le flurbiprofene axétil pourrait avoir un effet antiinflammatoire lors de chirurgies abdominales majeures. La combinaison de $F A$ intraveineux périopératoire, d'anesthésie péridurale thoracique peropératoire et d'APCP postopératoire a facilité le rétablissement de la fonction intestinale, amélioré l'analgésie, et atténué la sécrétion des cytokines.

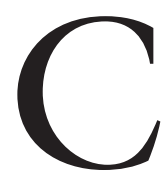
YTOKINES are a heterogeneous group of proteins which modulate the inflammatory response after surgery. Interleukin (IL)-6 and IL-8, released during inflammatory responses, could lead to prolonged hyperalgesia.., Also, these pro-inflammatory cytokines could indirectly modulate pain by altering pain signal transmission via cytokine-induced release of neuroactive substances, such as nitric oxide, oxygen-free radicals, and excitatory amino acids. ${ }^{3}$ Meanwhile, the anti-inflammatory cytokines also increase during inflammation to maintain a homeostatic balance. Interleukin-10 is an acute inflammatory mediator which down-regulates IL-6 and other pro-inflammatory cytokines through the transcription factor, nuclear kappa B. ${ }^{4}$ The balance of IL-6 and IL-10 is an important determinant of subsequent immune responses.

Colorectal surgery is associated with higher levels of IL- 6 than many other operations ${ }^{5}$ and is frequently associated with postoperative ileus. Up-regulation of pro-inflammatory cytokines has been shown to contribute to postoperative ileus. ${ }^{6,7}$ Accordingly, anesthetic interventions that modulate inflammatory responses might decrease the incidence and the severity of such complications, thereby minimizing morbidity and mortality.

Non-steroidal, anti-inflammatory drugs (NSAIDs) inhibit the synthesis of prostaglandins (PGs), both in the spinal cord and at the periphery, thus diminishing the hyperalgesia after surgical trauma. ${ }^{8,9}$ It is recommended that NSAIDs be used in a multimodal analgesic approach for the management of postoperative pain. ${ }^{10,11}$ Flurbiprofen axetil (FA), a non-selective cyclooxygenase (COX) inhibitor, is composed of emulsified lipid microspheres that have a high affinity to inflammatory tissues. ${ }^{12}$ It was reported that preoperative administration of FA could reduce postoperative pain after hysterectomy, ${ }^{13}$ pulpectomy, ${ }^{14}$ laparoscopic cholecystectomy, ${ }^{15}$ pediatric strabismus surgery, ${ }^{12}$ and spinal fusion surgery. ${ }^{16}$ Furthermore, flurbiprofen has been reported to protect against acute pancreatitis-associated lung injury and septic shock in rats. ${ }^{17,18}$ Recently, Takada et al. ${ }^{19}$ reported that premedication with flurbiprofen could suppress the local production of $\mathrm{PG} \mathrm{E}_{2}$ during tourniquet ischemia, resulting in reduced early postoperative pain in patients undergoing knee surgery. However, there are few data concerning whether perioperative FA might attenuate the release of cytokines and, therefore, improve postoperative pain and bowel function in patients undergoing open colorectal surgery.

Effective pain management is a prerequisite for the use of rehabilitation programs to accelerate recovery from surgery. ${ }^{20}$ The combination of thoracic epidural anesthesia and analgesia has been reported to reduce postoperative pain. ${ }^{21}$ Moreover, multimodal analgesia is regarded as the current trend in acute postoperative pain management. ${ }^{22}$ In this randomized, doubleblind, placebo-controlled study, we sought to evaluate the effects of perioperative intravenous FA, in combination with intraoperative thoracic epidural anesthesia and postoperative patient-controlled epidural analgesia (PCEA), on bowel function, postoperative pain, and perioperative cytokine response, in patients undergoing open colorectal surgery. It was hypothesized that intravenous FA would accelerate bowel function (time to first flatus and bowel movements) and enhance analgesia, while attenuating production of IL-6, IL-8, and IL-10 in the perioperative period.

\section{Methods}

Following approval of the study protocol by the Cancer Hospital, Fudan University Institutional Human Ethics Committee, and having obtained written informed consent, 40 ASA physical status I or II patients, aged 40-70 yr, undergoing elective surgery for colorectal cancer, were included in this prospective randomized, double-blind, placebo-controlled trial. The study was conducted over a period of five months, from October 2006 to February 2007. Patients with a known allergy to NSAIDs, those who had received chemotherapy 
and radiation prior to surgery, and anyone with a history of peptic ulceration, or renal, cardiac, endocrine, and/or hematological abnormalities were excluded. Patients who had received NSAIDs within 14 days before enrollment were also excluded. All surgical and anesthetic procedures were performed by the same team. Patients were familiarized with the visual analogue scale (VAS) and were instructed to use a PCEA pump (Ambit, West Jordan, UT, USA).

Patient randomization was established with the use of computer-generated codes. Allocation concealment was established by placing the randomization sequence in consecutively numbered, opaque envelopes. The study was performed by three investigators in a double-blinded manner as follows: Each test solution was prepared in a syringe by the first investigator, who was also responsible for subject grouping. The second investigator, who was blinded to the type of test solution, performed the intravenous injection. The variables were recorded by the third investigator, who was blinded to the type of test solution. The FA group received $1 \mathrm{mg} \cdot \mathrm{kg}^{-1} \mathrm{FA} i \mathrm{p}, 30 \mathrm{~min}$ before and six hours after skin incision, while the control group patients received intralipid intravenously as placebo.

\section{Anesthesia and analgesia}

The anesthetic regimen was standardized. All patients received a combined epidural/general technique. Central venous catheters were inserted before surgery. Patients received a volume preload with hydroxyethyl starch $\left(6 \%\right.$ HESI30/0.4) $12-14 \mathrm{~mL} \cdot \mathrm{kg}^{-1}$. Under sterile conditions, a thoracic epidural catheter was placed via the T9-12 interspace and was advanced $3-4 \mathrm{~cm}$ cephalad. A test dose of $1 \%$ lidocaine $3 \mathrm{~mL}$, alone, was then given via the thoracic epidural catheter, followed by $0.5 \%$ ropivacaine $5 \mathrm{~mL}$, to produce a bilateral segmental sensory block to pinprick between the T6 and L2 dermatomes. The neuraxial block was maintained with $0.5 \%$ ropivacaine $4-8 \mathrm{~mL} \cdot \mathrm{hr}^{-1}$ throughout the surgical procedure.

General anesthesia was induced with an intravenous injection of midazolam $\left(0.03 \mathrm{mg} \cdot \mathrm{kg}^{-1}\right)$, fentanyl (2 $\left.\mu \mathrm{g} \cdot \mathrm{kg}^{-1}\right)$, and propofol $\left(\mathrm{l}-2 \mathrm{mg} \cdot \mathrm{kg}^{-1}\right)$. Tracheal intubation was facilitated with $0.1 \mathrm{mg} \cdot \mathrm{kg}^{-1}$ vecuronium $i v$. Thereafter, no additional opioid was given. Ventilation was mechanically controlled to maintain the partial pressure of expiratory carbon dioxide between 30 and $35 \mathrm{mmHg}$. General anesthesia was maintained with isoflurane in oxygen. Isoflurane concentration was adjusted to maintain blood pressure and heart rate within $20 \%$ of respective baseline values. Vecuronium was used to maintain muscular blockade. Heart rate (by electrocardiography), $\mathrm{CO}_{2}$ production (by cap- nography), arterial blood pressure, central venous pressure, and blood oxygen saturation (by pulse oximetry) were monitored. Hypotension (systolic arterial blood pressure $<90 \mathrm{mmHg}$ ) was treated by increasing the rate of intravenous fluid infusion and by administering ephedrine $10 \mathrm{mg} i v$. At the end of surgery, residual, neuromuscular block was antagonized with neostigmine $40 \mu \mathrm{g} \cdot \mathrm{kg}^{-1}$ and atropine $0.01 \mathrm{mg} \cdot \mathrm{kg}^{-1} i$, and, when the patient resumed spontaneous ventilation, the endotracheal tube was removed.

Upon arrival in the postanesthesia care unit, patients were connected to the PCEA pump through the thoracic epidural catheter, and they received an initial loading dose of morphine $2 \mathrm{mg}$ iv for pain relief. Patients in both groups received PCEA with morphine $\left(0.025 \mathrm{mg} \cdot \mathrm{mL}^{-1}\right)$ and ropivacaine $(0.125 \%)$ in $200 \mathrm{~mL}$ $0.9 \%$ sodium chloride (bolus $2 \mathrm{~mL}$, lockout time 20 min, background infusion $3 \mathrm{~mL} \cdot \mathrm{hr}^{-1}$ ). The segmental sensory block was assessed on a daily basis by a blinded investigator testing by pinprick. The PCEA medication was discontinued on postoperative day three. A 10-cm VAS (with endpoints labelled "no pain" and "worst possible pain") was used to assess pain intensity at rest and during coughing at one, two, four, eight, 24,48 , and $72 \mathrm{hr}$ postoperatively. We also recorded bowel function (time to first flatus and first bowel movement) and the side effects related to morphine (drowsiness, dizziness, nausea, and vomiting) for 72 hr postoperatively. Nausea was measured using a VAS $(0=$ no nausea, $10=$ worst imaginable nausea $)$ scoring system. A postoperative nausea and vomiting episode was defined as the occurrence of nausea (score 1-10), vomiting, or need for rescue antiemetic therapy.

\section{Perioperative care}

All patients were instructed about the standard intraoperative and postoperative care for their surgery. Routine mechanical bowel preparation consisted of a clear liquid diet and polyethylene glycol 3 L administered the day prior to surgery. Antibiotic prophylaxis was provided with metronidazole $500 \mathrm{mg} i v$ and cefotiam $2 \mathrm{~g} i v, 30 \mathrm{~min}$ prior to skin incision. A nasogastric tube was used in all patients

A Foley urinary bladder catheter was inserted after induction of general anesthesia. The catheter remained in situ until the epidural catheter was removed. After surgery, an intravenous infusion of Ringer's lactate/ dextrose was started and continued for a minimum of $48 \mathrm{hr}$. All patients were encouraged to mobilize on the first postoperative day and to progressively ambulate. Patients were only allowed sips of water during the first 24 postoperative hours. Oral fluids were started as soon as the patients passed flatus. Nutritional supple- 


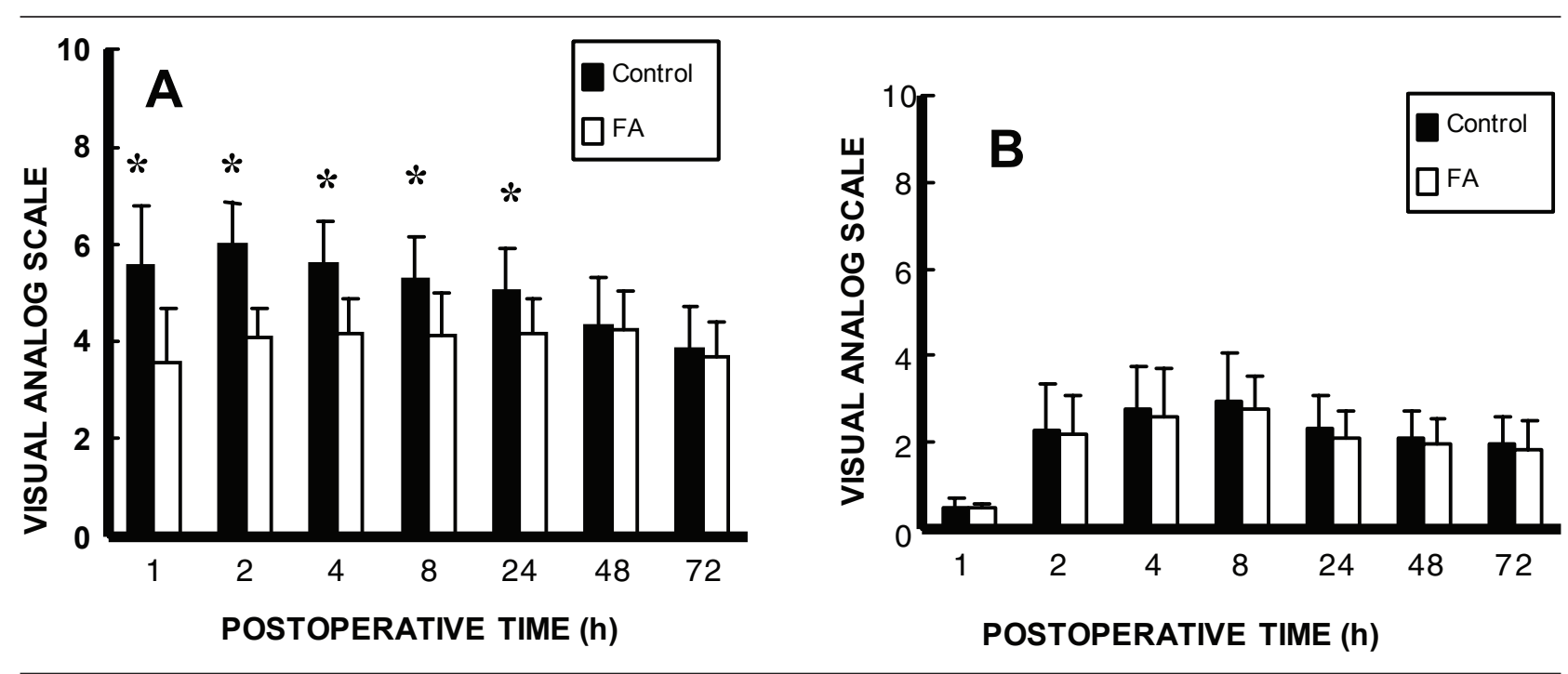

FIGURE 1 Visual analogue scale (VAS) pain scores during coughing (A) and at rest (B). Resting VAS values were not significantly different between groups. Coughing VAS was significantly higher at one, two, four, eight and $24 \mathrm{hr}$ in the control group compared with the FA group. Values are mean $\pm S D ;{ }^{*} P<0.001$ compared with the FA group. FA $=$ flurbiprofen axetil.

ments, provided in liquid form, consisted of up to $60 \mathrm{~g}$ of protein and 1,200 calories. The oral supplement was subsequently changed to either a semi-solid or a solid form, depending on the presence of bowel movement and the tolerance to diet (no vomiting or bowel distension).

\section{Outcome measurements}

The primary outcome measure was return of bowel function (time to first flatus and bowel movement). Secondary outcome measures included postoperative VAS pain scores, plasma levels of IL-6, IL-8, and IL-10, leukocyte count, and body temperature.

Peripheral, venous blood samples were withdrawn ten minutes before FA infusion, at the end of surgery, and six hours and $24 \mathrm{hr}$, postoperatively. Blood was collected into EDTA (ethylenediaminetetraacetic acid) tubes and was immediately centrifuged at $3000 \mathrm{rpm}$ for ten minutes at $4^{\circ} \mathrm{C}$. Thereafter, plasma was stored at $-20^{\circ} \mathrm{C}$ for future measurement. Plasma levels of IL-6, IL-8, and IL-10 were measured with commercially available quantitative sandwich enzyme-linked immunosorbent assay kits (Quantikine; R\&D Systems, Minneapolis, MN, USA). The sensitivities of the assays for IL-6, IL-8, and IL-10 were 2, 7, and $15 \mathrm{pg} \cdot \mathrm{mL}^{-1}$, respectively. The intraassay and interassay coefficients of variation of the immunoassay kits ranged from 5 to $10 \%$, inclusive.

\section{Sample size and statistical analysis}

The primary outcome measure of this study was the time to first bowel movement. The sample size was based upon previously published studies ${ }^{23,24}$ and, with an alpha level of 0.05 and a power of $80 \%$, a minimum of 18 patients per group was required to detect a 12-hr difference in the recovery of bowel movements between groups. Bowel function (time to first flatus and time to first bowel movements) was analyzed by Student's $t$ test. Visual analogue scale scores were compared using Student's $t$ test. Plasma levels of IL-6, IL-8, and IL-10, leukocyte count, and temperature were compared using repeated-measures analysis of variance (ANOVA). With the exception of VAS pain scores, all data are presented as mean \pm SD. $P<0.05$ was considered statistically significant.

\section{Results}

Forty-four patients undergoing elective surgery for colorectal cancer met the study inclusion criteria. Four patients declined participation, leaving 40 patients who were randomized and assigned in equal numbers to either group. All 40 patients completed the study protocol, and data from all subjects were included in the final analysis.

The groups were similar with respect to mean age, body weight, height, male/female ratio, and type and duration of surgery (Table I). The time intervals from surgery to the first flatus and the first bowel movement resumed between $12 \mathrm{hr}$ and $18 \mathrm{hr}$ earlier, on average, in the FA group $p s$ the control group $(P=0.01, P=$ 0.008 , respectively. Table II). Intraoperative blood loss and the incidence of postoperative nausea and 
TABLE I Demographic and clinical data

\begin{tabular}{lll}
\hline & Control $(n=20)$ & FA $(n=20)$ \\
\hline Age (yr) & $56 \pm 9$ & $53 \pm 7$ \\
Gender (M/F) & $11 / 9$ & $12 / 8$ \\
Body height (cm) & $164 \pm 8$ & $165 \pm 7$ \\
Body weight (kg) & $62 \pm 11$ & $64 \pm 7$ \\
ASA status (I/II) & $8 / 12$ & $11 / 9$ \\
Type of surgery & & \\
Hemicolectomy (right) & 8 & 7 \\
Hemicolectomy (left) & 6 & 8 \\
Sigmoid colectomy & 3 & 2 \\
Anterior rectal resection & 3 & 3 \\
Operation time (min) & $133 \pm 16$ & $130 \pm 16$
\end{tabular}

$\mathrm{M}=$ male $; \mathrm{F}=$ female $; \mathrm{FA}=$ flurbiprofen axetil. Values are mean \pm SD except for gender, ASA status and type of surgery.

TABLE II Postoperative recovery of gastrointestinal function and adverse events

\begin{tabular}{llll}
\hline & $\begin{array}{l}\text { Control } \\
(n=20)\end{array}$ & $\begin{array}{l}\text { FA } \\
(n=20)\end{array}$ & $P$ value \\
\hline $\begin{array}{l}\text { Time to first pass } \\
\text { of flatus (hr) }\end{array}$ & $75 \pm 11$ & $63 \pm 16$ & 0.01 \\
$\begin{array}{l}\text { Time to first bowel } \\
\text { movements }\end{array}$ & $105 \pm 19$ & $87 \pm 23$ & 0.01 \\
$\begin{array}{l}\text { Blood loss (mL) } \\
\text { Nausea }(n)\end{array}$ & $216 \pm 41$ & $223 \pm 49$ & 0.61 \\
Vomiting $(n)$ & 5 & 8 & \\
\hline
\end{tabular}

Values are mean \pm SD. FA $=$ flurbiprofen axetil.

vomiting were similar in both groups (Table II). No patient suffered any adverse effects.

All patients received an identical PCEA regimen. After surgery, segmental sensory blocks were maintained between the T7 and Ll dermatomes. There were no epidural failures (disconnection, leak, dislodgement) during the postoperative period. The cumulative amounts of morphine and ropivacaine administered were $7 \mathrm{mg}$ and $250 \mathrm{mg}$, respectively. Compared with the patients in the control group, those in the FA group experienced lower VAS scores during coughing at one, two, four, eight, and $24 \mathrm{hr}$, postoperatively (Figure 2A, Table III). However, there were no significant between-group differences in the VAS scores at rest (Figure 2B, Table III).

Interleukin- 6 increased during surgery and peaked at six hours postoperatively, in both groups $(P<$ 0.0001 , Figure 3 , Table IV). Interleukin-6 levels were lower $(P<0.01$, Figure 3 , Table IV) at the end of surgery, six hours and $24 \mathrm{hr}$ postoperatively, in the FA group. At six hours postoperatively, IL-6 levels were significantly lower in the FA group compared with the control group $(P=0.004$, Figure 3 , Table IV).

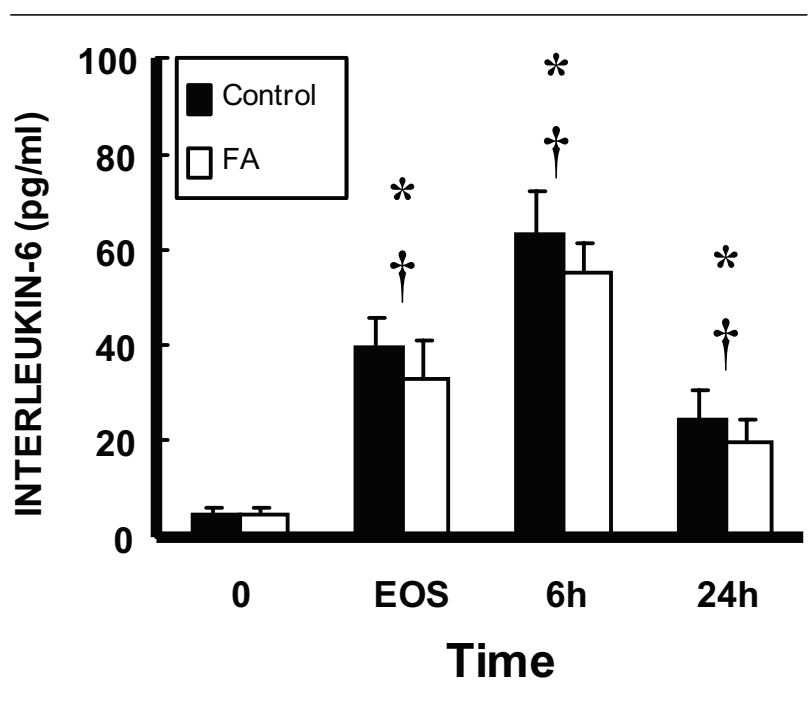

FIGURE 2 Mean plasma concentrations of interleukin (IL)-6. Values shown are mean $\pm \mathrm{SD}$. FA = flurbiprofen axetil; $0=$ baseline; EOS = end of the surgery; $6 \mathrm{hr}$ and $24 \mathrm{hr}=$ six and $24 \mathrm{hr}$ after surgery. ${ }^{*} P<0.0001$, postoperative values $v$ s baseline levels in both groups, $\uparrow P<0.01$; FA vs control group.

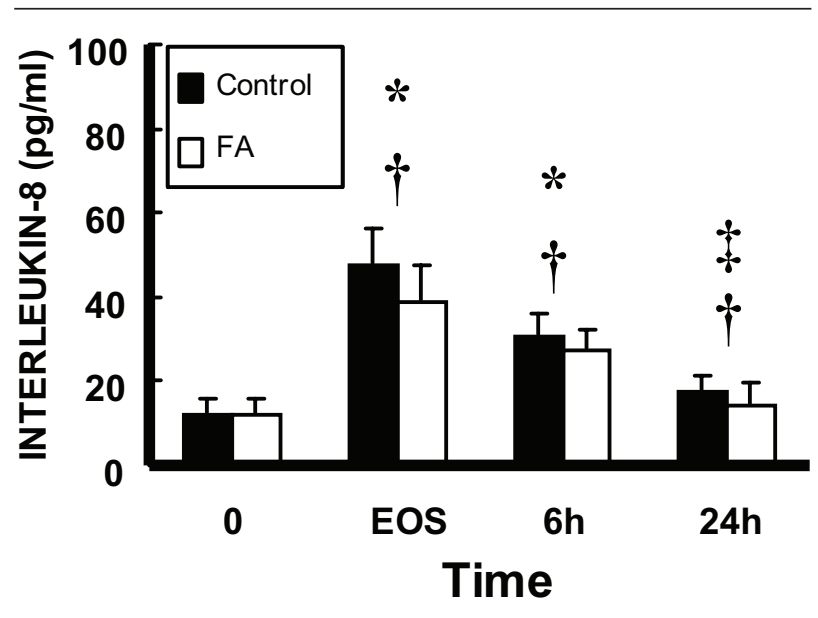

FIGURE 3 Mean plasma concentrations of interleukin (IL)-8. Values shown are mean $\pm \mathrm{SD}$. FA $=$ flurbiprofen axetil; $0=$ baseline; EOS = end of the surgery; $6 \mathrm{hr}$ and $24 \mathrm{hr}=$ six and $24 \mathrm{hr}$ after surgery. ${ }^{*} P<0.0001$, postoperative values $v$ s baseline levels in both groups. $\dagger P<0.05$, FA vs control group. $\ddagger P<0.0001$, postoperative values $v s$ baseline levels in control group.

Interleukin- 8 increased during surgery and peaked at the end of surgery in both groups $(P<0.0001$, Figure 4, Table IV). Interleukin-8 levels were lower $(P<0.05$, Figure 4 , Table IV $)$ at the end of surgery, six hours and $24 \mathrm{hr}$ postoperatively, in the FA group. At the end of the surgery, IL-8 levels were significantly lower in the FA group compared with corresponding values in the control group $(P=0.002$, Figure 4 , Table IV). 
TABLE III Visual analogue scale pain scores at rest and during coughing

\begin{tabular}{llll}
\hline & Control $(n=20)$ & FA $(n=20)$ & $P$ value \\
\hline VAS at rest $(\mathrm{cm})$ & & & \\
$1 \mathrm{hr}$ & $0.4(0.3-0.5)$ & $0.4(0.4-0.5)$ & 1.0 \\
$2 \mathrm{hr}$ & $2.1(1.9-2.2)$ & $1.9(1.8-2.0)$ & 0.70 \\
$4 \mathrm{hr}$ & $2.6(2.4-2.9)$ & $2.3(2.2-2.5)$ & 0.69 \\
$8 \mathrm{hr}$ & $3.0(2.9-3.1)$ & $2.8(2.5-2.9)$ & 0.49 \\
$24 \mathrm{hr}$ & $2.2(2.0-2.3)$ & $2.1(1.9-2.2)$ & 0.45 \\
$48 \mathrm{hr}$ & $2.0(1.9-2.1)$ & $1.9(1.7-2.0)$ & 0.47 \\
$72 \mathrm{hr}$ & $1.8(1.7-1.9)$ & $1.7(1.6-1.9)$ & 0.69 \\
$V A S$ during & & & \\
coughing $(\mathrm{cm})$ & & & \\
$1 \mathrm{hr}$ & $5.8(4.6-6.0)$ & $3.5(3.1-3.7)$ & $<0.001$ \\
$2 \mathrm{hr}$ & $6.0(5.7-6.3)$ & $4.0(3.8-4.2)$ & $<0.001$ \\
$4 \mathrm{hr}$ & $5.7(5.3-5.8)$ & $4.0(3.8-4.3)$ & $<0.001$ \\
$8 \mathrm{hr}$ & $5.2(4.9-5.3)$ & $3.9(3.8-4.0)$ & $<0.001$ \\
$24 \mathrm{hr}$ & $4.8(4.5-5.3)$ & $4.0(3.6-4.7)$ & 0.001 \\
$48 \mathrm{hr}$ & $4.1(4.0-4.5)$ & $4.1(3.7-4.2)$ & 0.71 \\
$72 \mathrm{hr}$ & $3.9(3.5-4.0)$ & $3.6(3.5-3.9)$ & 0.58 \\
\hline
\end{tabular}

Data are presented as median (interquartile range).

$\mathrm{FA}=$ flurbiprofen axetil; VAS $=$ visual analogue scale .

TABLE IV Effects of FA on cytokine plasma levels

\begin{tabular}{llll}
\hline & Control $(n=20)$ & FA $(n=20)$ & $P$ value \\
\hline$I L-6\left(p g \cdot m L^{-1}\right)$ & & & \\
0 & $5.04 \pm 1.13$ & $4.96 \pm 1.20$ & 0.847 \\
EOS & $39.86 \pm 5.54^{*}$ & $33.03 \pm 7.53^{*}$ & 0.002 \\
$6 \mathrm{hr}$ & $62.93 \pm 9.12^{*}$ & $55.28 \pm 6.15^{*}$ & 0.004 \\
$24 \mathrm{hr}$ & $24.61 \pm 5.84^{*}$ & $19.38 \pm 5.22^{*}$ & 0.005 \\
$I L-8\left(p g \cdot m L^{-1}\right)$ & & & \\
0 & $12.53 \pm 3.50$ & $12.36 \pm 3.55$ & 0.876 \\
EOS & $47.86 \pm 8.45^{*}$ & $39.37 \pm 8.06^{*}$ & 0.002 \\
$6 \mathrm{hr}$ & $31.38 \pm 4.78^{*}$ & $28.03 \pm 4.44^{*}$ & 0.027 \\
$24 \mathrm{hr}$ & $18.08 \pm 3.48^{*}$ & $14.67 \pm 4.75$ & 0.013 \\
$I L-10\left(p g \cdot m L^{-1}\right)$ & & & \\
0 & $5.59 \pm 1.22$ & $5.77 \pm 1.15$ & 0.635 \\
EOS & $17.88 \pm 5.0^{*}$ & $18.48 \pm 5.06^{*}$ & 0.710 \\
$6 \mathrm{hr}$ & $15.90 \pm 6.96^{*}$ & $31.65 \pm 6.20^{*}$ & 0.009 \\
$24 \mathrm{hr}$ & $15.48 \pm 4.82^{*}$ & $16.40 \pm 5.78^{*}$ & 0.584 \\
\hline
\end{tabular}

Data are mean $\pm \mathrm{SD} .{ }^{*} P<0.0001$ vs baseline values. $\mathrm{FA}=$ flurbiprofen axetil; $0=$ baseline; EOS = end of the surgery; $6 \mathrm{hr}$ and $24 \mathrm{hr}=$ six and $24 \mathrm{hr}$ after surgery.

Interleukin-10 also increased during surgery and peaked at six hours in both groups $(P<0.0001$, Figure 5, Table IV). At six hours, IL-10 levels were significantly higher in the FA group compared with those in the control group $(P=0.009$, Figure 4 , Table IV).

In both groups, at $24 \mathrm{hr}$ after surgery, leukocyte count and body temperature were higher than before surgery and were significantly lower for patients in the FA group compared with those of control group $(P=$ $0.001, P=0.006$ respectively, Table V).

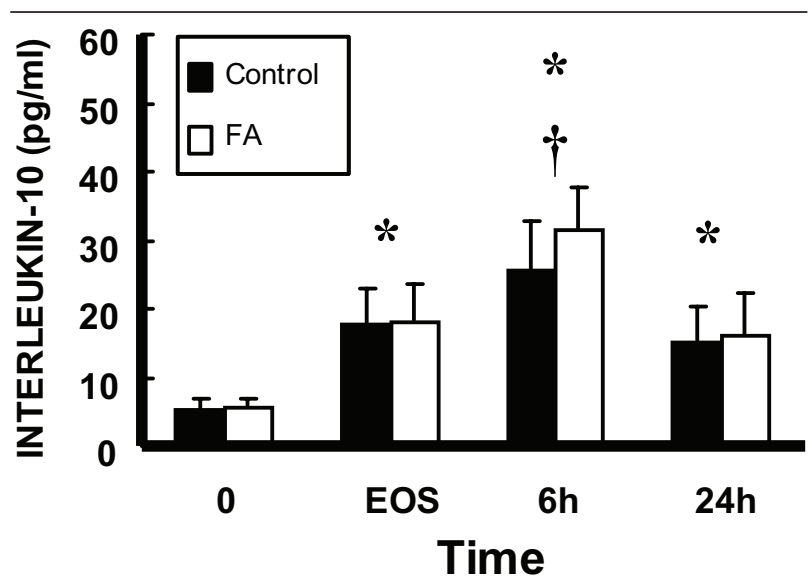

FIGURE 4 Mean plasma concentrations of interleukin (IL)-10. Values shown are mean $\pm \mathrm{SD}$. FA $=$ flurbiprofen axetil; $0=$ baseline; EOS = end of the surgery; $6 \mathrm{hr}$ and $24 \mathrm{hr}=$ six and $24 \mathrm{hr}$ after surgery. ${ }^{*} P<0.0001$, postoperative values $v$ s baseline levels in both groups. $\dagger P=0.009$, FA $v s$ control group.

TABLE V Leukocyte count and temperature changes after surgery

\begin{tabular}{llll}
\hline & Control $(n=20)$ & FA $(n=20)$ & $P$ value \\
\hline $\begin{array}{l}\text { Leukocyte count } \\
\left(\times 10^{9} \mathrm{~L}^{-1}\right)\end{array}$ & & & \\
Before surgery & $6.2 \pm 1.46$ & $6.2 \pm 1.22$ & 0.92 \\
$24 \mathrm{hr}$ & $10.8 \pm 1.88^{*}$ & $9.1 \pm 1.02^{*}$ & 0.001 \\
Temperature $\left({ }^{\circ} \mathrm{C}\right)$ & & & \\
Before surgery & $36.9 \pm 0.17$ & $36.9 \pm 0.14$ & 0.66 \\
$24 \mathrm{hr}$ & $37.9 \pm 0.39^{*}$ & $37.6 \pm 0.38^{*}$ & 0.006 \\
\hline
\end{tabular}

Values are mean $\pm \mathrm{SD}$. *Significantly higher than before surgery. $P<0.001 ; \mathrm{FA}=$ flurbiprofen axetil.

\section{Discussion}

In the present study, perioperative intravenous administration of flurbiprofen axetil, combined with intraoperative administration of $0.5 \%$ ropivacaine via thoracic epidural, accelerated recovery of the bowel function, resulted in less severe postoperative pain, and attenuated production of IL-6, IL-8, and IL-10.

Previous studies reported that preoperative administration of FA reduces postoperative pain. Our data also suggest that administration of FA as a multimodal analgesic adjuvant, can improve the overall quality of postoperative pain management. The improvement in pain control is likely the result of perioperative COX inhibition. ${ }^{12-16,19}$ Reduction of PG synthesis would be expected to diminish nociceptor sensitization and inflammatory responses that normally accompany movement and stretching of injured tissues. ${ }^{25-27}$ The COX selectivity of FA remains unclear, although it was 
speculated that FA might have an equivalent selectivity for COX-1 and COX-2.28

In the present study, the dose of FA was adopted on the basis of values reported in the literature. ${ }^{13,14}$ Since the analgesic effect of FA usually begins $30 \mathrm{~min}$ after administration, with an elimination half-life of six hours, we administered FA 30 min before and six hours after skin incision in the FA group.

Interleukin-6, a key pro-inflammatory cytokine, is produced in substantial quantities at the surgical wound ${ }^{29}$ and then enters the systemic circulation where its concentration correlates with the severity of surgery and the magnitude of tissue injury. ${ }^{5}$ Interleukin-6 levels in the circulation are detectable within 60 min after injury, peak at about four to six hours, and can persist for as long as ten days. ${ }^{30}$ Moreover, IL6 can induce peripheral and central nervous system sensitization leading to hyperalgesia. ${ }^{31}$ Although some anesthetic agents may affect cytokine release, there is little evidence for clinically relevant modulation of the inflammatory response by anesthesia. Combined epidural/general anesthesia, as used in the present study, did not result in reduction of IL-6 concentration compared with general anesthesia alone. ${ }^{32,33} \mathrm{In}$ this study, IL-6 increased in all patients during surgery; however, peak concentrations were significantly lower in patients who received FA treatment. This may be a direct effect of FA, since both groups had a similar degree of tissue injury, with similar anesthetic and surgical management. Therefore, the effect of FA might account for the attenuation of IL-6 production.

Our results are consistent with other studies showing attenuated IL-6 production in major surgery after NSAIDs administration. ${ }^{34,35}$ Flurbiprofen axetil has a high affinity to inflammatory tissues, and, in this regard, FA may behave differently from other NSAIDs. We plan to use other NSAIDs as active controls in future studies.

Interleukin- 8 has the potential to recruit neutrophils and monocytes into the inflammatory site, thus accelerating inflammation. ${ }^{36}$ Its release and activity is temporally associated with IL-6 after surgery. ${ }^{30}$ Interleukin- 8 is the first endogenous mediator that is identified to evoke hyperalgesia in which the sympathetic nervous system is involved. ${ }^{2}$ Interleukin- 8 is released by activated macrophages and endothelial cells and may act as a humoral link between tissue injury and sympathetic hyperalgesia. Our results suggest that perioperative FA administration could decrease perioperative plasma levels of IL-8 and may provide more effective pain relief. In the present study, IL-6 and IL-8 levels were reduced by FA, but the extent of this reduction is relatively small compared with the overall response to surgery. This finding supports the concept that perioperative iv FA is able to attenuate, but not suppress, cytokine release.

It has been previously suggested that IL-10 has strong anti-inflammatory activities which increase during major surgery. ${ }^{37}$ The present study demonstrates that the maximum value of IL-10 was achieved within six hours following surgery in the two groups, which correlated with the increase of IL- 6 levels. Meanwhile, FA treatment increased IL-10 release at six hours after surgery, consistent with previous studies showing higher IL-10 production in major surgery after NSAID administration. ${ }^{34,35}$ There seems to be a negative feedback between PG synthesis and IL-10 production. Prostaglandins played a key role in the induction of IL-10 in human monocytes, and, in turn, IL-10 inhibited PG production. ${ }^{38}$ Thus, the alteration of IL-10 concentration by NSAIDs seems to induce anti-inflammatory effects by inhibiting PG production through the IL-10 response.

Abdominal surgery is often accompanied by postoperative ileus. Despite its normally benign and self-limiting character, it is associated with patient discomfort, prolonged hospitalization, and increased postoperative morbidity. Postoperative ileus also has a significant economic impact, since it results in approximately $\$ 1$ billion of additional expense in the United States each year. ${ }^{39}$ Flurbiprofen axetil is composed of emulsified lipid microspheres that have a high affinity to inflammatory tissues. Since inflammation plays a crucial role in postoperative ileus, intravenous FA may mediate its beneficial effects by promoting gastrointestinal motility and by targeting different steps within this inflammatory cascade. In our study, perioperative administration of FA significantly attenuated the surgery-induced increase of IL-6 and IL-8. IL-6 cytokines are well known for their role in maintaining postoperative ileus and intestinal permeability disorders. ${ }^{5-7}$ The diminished cytokine response was associated with more rapid recovery of bowel function, as shown in the present study. The results are consistent with an after surgery, up-regulation and release of the pro-inflammatory cytokines that contribute to postoperative ileus. ${ }^{7}$

The attenuated rise in body temperature $\left(0.3^{\circ} \mathrm{C}\right)$ observed in the FA group can be attributed to the antipyretic effect of NSAIDs. This effect on fever shows that perioperative, intravenous FA may reduce nitrogen losses after colorectal surgery. At $24 \mathrm{hr}$ after surgery, leukocyte counts in the FA group were mildly reduced, but mean levels were well within the normal range. Flurbiprofen axetil may have an anti-inflammatory effect in major abdominal surgery. 
There are several limitations of the current study. First, we did not examine the opioid-sparing effect of FA. We focused on the effect of FA on bowel function and cytokine response. Secondly, we only measured cytokines over a $24-\mathrm{hr}$ postoperative period. Compared to baseline values, the cytokine levels remained higher at the end of $24 \mathrm{hr}$. Cytokine concentrations may continue to decline for approximately $24-36 \mathrm{hr}$ following surgery. ${ }^{5}$ Thirdly, our study only showed an analgesic benefit with $\mathrm{FA}$ for the first $24 \mathrm{hr}$ postoperatively. Therefore, further studies would be required to evaluate the optimal intravenous dosage of FA to provide continuous analgesia, early recovery of bowel function, and analgesic-sparing properties with minimal side effects.

In conclusion, the combination of perioperative intravenous FA, intraoperative thoracic epidural anesthesia, and postoperative PCEA may provide faster recovery of bowel function and improve postoperative pain control, while attenuating production of IL- 6 , IL-8, and IL-10 in the perioperative period. These findings further support the role of FA, a non-selective COX inhibitor, as part of a multimodal analgesic regimen. Flurbiprofen axetil may have an anti-inflammatory role in major abdominal surgery. Finally, we suggest that perioperative intravenous administration of FA, combined with thoracic epidural anesthesia and postoperative PCEA, may be a potential therapeutic strategy in fast-track rehabilitation programs.

\section{References}

1 Lavand'homme P, De Kock M, Waterloos H. Intraoperative epidural analgesia combined with ketamine provides effective preventive analgesia in patients undergoing major digestive surgery. Anesthesiology 2005; 103: 813-20.

2 Cunba FQ Lorenzetti BB, Poole S, Ferreira SH. Interleukin- 8 as a mediator of sympathetic pain. Br J Pharmacol 1991; 104: 765-7.

3 Watkins LR, Milligan ED, Maier SF. Glial proinflammatory cytokines mediate exaggerated pain states: implications for clinical pain. Adv Exp Med Biol 2003; 502: 1-21.

4 Schottelius AJ, Mayo MW, Sartor RB, Baldwin AS Jr. Interleukin-10 signaling blocks inhibitor of kappa $\mathrm{B}$ kinase activity and nuclear factor kappa B DNA binding. J Biol Chem 1999; 274: 31868-74.

5 Cruickshank AM, Fraser WD, Burns HJ, Van Damme $J$, Shenkin A. Response of serum interleukin-6 in patients undergoing elective surgery of varying severity. Clin Sci (Lond) 1990; 79: 161-5.

6 Wang W, Smail N, Wang P, Chaudry IH. Increased gut permeability after hemorrhage is associated with upregulation of local and systemic IL-6. J Surg Res 1998; 79: 39-46.

7 Kalff JC, Turler A, Schwarz NT, et al. Intra-abdominal activation of a local inflammatory response within the human muscularis externa during laparotomy. Ann Surg 2003; 237: 301-15.

8 McCormack K. Non-steroidal anti-inflammatory drugs and spinal nociceptive processing. Pain 1994; 59: 9-43.

9 Souter AJ, Fredman B, White PF. Controversies in the perioperative use of nonsteroidal antiinflammatory drugs. Anesth Analg 1994; 79: 1178-90.

10 Keblet H, Dahl JB. The value of "multimodal" or "balanced analgesia" in postoperative pain treatment. Anesth Analg 1993; 77: 1048-56.

11 Anonymous. Practice guidelines for acute pain management in the perioperative setting. A report by the American Society of Anesthesiologists Task Force on Pain Management, Acute Pain Section. Anesthesiology 1995; 82: 1071-81.

12 Mikawa K, Nishina K, Maekawa N, Shiga M, Obara $H$. Dose-response of flurbiprofen on postoperative pain and emesis after paediatric strabismus surgery. Can J Anaesth 1997; 44: 95-8.

13 Nakayama M, Ichinose H, Yamamoto S, Nakabayashi $K$, Satoh $O$, Namiki A. Perioperative intravenous flurbiprofen reduces postoperative pain after abdominal hysterectomy. Can J Anesth 2001; 48: 234-7.

14 Flath RK, Hicks ML, Dionne RA, Pelleu GB Jr. Pain suppression after pulpectomy with preoperative flurbiprofen. J Endod 1987; 13: 339-47.

15 Tanaka S, Sonoda H, Nakabayashi K, Namiki A.Preoperative flurbiprofen provides pain relief after laparoscopic cholecystectomy (Japanese). Masui 1997; 46: 679-83.

16 Yamashita K, Fukusaki M, Ando , et al. Preoperative administration of intravenous flurbiprofen axetil reduces postoperative pain for spinal fusion surgery. J Anesth 2006; 20: 92-5.

17 Huang J, Moochbala SM, Moore PK, Bhatia M. Flurbiprofen and HCT1026 protect mice against acute pancreatitis-associated lung injury. Shock 2005; 24 : 182-7.

18 Anuar F, Whiteman M, Bhatia M, Moore PKl. Flurbiprofen and its nitric oxide-releasing derivative protect against septic shock in rats. Inflamm Res 2006; 55 : 498-503.

19 Takada M, Fukusaki M, Terao , et al. Preadministration of flurbiprofen suppresses prostaglandin production and postoperative pain in orthopedic patients undergoing tourniquet inflation. J Clin Anesth 2007; 19: 97-100. 
20 Keblet H, Dahl JB. Anaesthesia, surgery, and challenges in postoperative recovery. Lancet 2003; 362: 1921-8.

21 Rigg JR, Jamrozik K, Myles PS, et al. Epidural anaesthesia and analgesia and outcome of major surgery: a randomised trial. Lancet 2002; 359: 1276-82.

22 Kissin I. Preemptive analgesia. Anesthesiology 2000; 93: $1138-43$.

23 Carli F, Trudel JL, Bellivean P. The effect of intraoperative thoracic epidural anesthesia and postoperative analgesia on bowel function after colorectal surgery: a prospective, randomized trial. Dis Colon Rectum 2001; 44: 1083-9.

24 Hong X, Mistraletti G, Zandi S, Stein B, Charlebois P, Carli $F$. Laparoscopy for colectomy accelerates restoration of bowel function when using patient controlled analgesia. Can J Anesth 2006; 53: 544-50.

25 Lin J, Ding $\Upsilon$, White PF, Feinstein R, Shear JM. Effect of ketorolac on postoperative analgesia and ventilatory function after laparoscopic cholecystectomy. Anesth Analg 1993; 76: 1061-6.

26 Seibert K, Masferrer JL. Role of inducible cyclooxygenase (COX-2) in inflammation. Receptor 1994; 4: 17-23.

27 Sinatra RS, Shen QJ, Halaszynski T, Luther MA, Shabeen $\Upsilon$. Preoperative rofecoxib oral suspension as an analgesic adjunct after lower abdominal surgery: the effects on effort-dependent pain and pulmonary function. Anesth Analg 2004; 98: 135-40.

28 Svensson CI, Yaksh TL. The spinal phospholipasecyclooxygenase-prostanoid cascade in nociceptive processing. Ann Rev Pharmacol Toxicol 2002; 42: 553-83.

29 Holzheimer RG, Steinmetz W. Local and systemic concentrations of pro- and anti-inflammatory cytokines in human wounds. Eur J Med Res 2000; 5: 347-55.

30 Lin E, Calvano SE, Lowry SF, Goebler LE. Inflammatory cytokines and cell response in surgery. Surgery 2000; 127: 117-26.

31 Watkins LR, Maier SF. Immune activation: the role of pro-inflammatory cytokines in inflammation, illness responses and pathological pain states. Pain 1995; 63: 289-302.

32 Volk T, Schenk M, Voigt K, Tobtz S, Putzier M, Kox WJ. Postoperative epidural anesthesia preserves lymphocyte, but not monocyte, immune function after major spine surgery. Anesth Analg 2004; 98: 1086-92.

33 Yokoyama $M$, Itano $\Upsilon$, Katayama $H$, et al. The effects of continuous epidural anesthesia and analgesia on stress response and immune function in patients undergoing radical esophagectomy. Anesth Analg 2005; 101: 1521-7.

$34 \mathrm{Kim}$ MH, Hahm TS. Plasma levels of interleukin-6 and interleukin-10 are affected by ketorolac an an adjunct to patient-controlled morphine after abdominal hysterectomy. Clin J Pain 2001; 17: 72-7.

35 Mabdy AM, Galley HF, Abdel-Wahed MA, el-Korny $K F$, Sheta $S A$, Webster NR. Differential modulation of interleukin- 6 and interleukin- 10 by diclofenac in patients undergoing major surgery. Br J Anaesth 2002; 88: 797-802.

36 Gale LM, McColl SR. Chemokines: extracelluar messengers for all occasions? Bioessays 1999; 21: 17-28.

37 Giannoudis PV, Smith RM, Perry SL, Windsor AJ, Dickson RA, Bellamy MC. Immediate IL-10 expression following major orthopaedic trauma: relationship to anti-inflammatory response and subsequent development of sepsis. Intensive Care Med 2000; 26: 107681.

38 Nibo $\Upsilon$, Niiro H, Tanaka $\Upsilon$, Nakashima H, Otsuka T. Role of IL-10 in the crossregulation of prostaglandins and cytokines in monocytes. Acta Haematol 1998; 99: 165-70.

39 Prasad M, Matthews JB. Deflating postoperative ileus. Gastroenterology 1999; 117: 489-92. 